Relationship Between Self-Compassion and Depression in Cancer Patients Referring to the Oncology Ward of Shahid Baghaee Hospital

\title{
in Ahvaz, Iran
}

\author{
Yaghoob Madmoli ${ }^{1}$, Mahin Gheibizadeh (iD ${ }^{2,}{ }^{*}$, Maryam Fazeli ${ }^{1}$, Parvin Ghezelbash ${ }^{2}$ and Mostafa \\ Madmoli $^{3}$ \\ ${ }^{1}$ Student Research Committee, Ahvaz Jundishapur University of Medical Sciences, Ahvaz, Iran \\ ${ }^{2}$ Nursing Care Research Center in Chronic Disease, Nursing and Midwifery School, Ahvaz Jundishapur University of Medical Sciences, Ahvaz, Iran \\ ${ }^{3}$ Dezful University of Medical Sciences, Dezful, Iran \\ "Corresponding author: PhD in Nursing, Assistant Professor, Nursing Care Research Center in Chronic Disease, Nursing and Midwifery School, Ahvaz Jundishapur University of \\ Medical Sciences, Ahvaz, Iran. Emails: gheibizadeh-m@ajums.ac.ir; mgheibizadeh@yahoo.com
}

Received 2018 August 18; Revised 2019 June 10; Accepted 2019 June 13.

\begin{abstract}
Background: Depression is one of the most common psychiatric diseases in cancer patients. Few studies showed that selfcompassion is a reliable predictor of mental health.

Objectives: This study aimed to determine the relationship between self-compassion and depression in cancer patients referring to the Oncology Ward of Shahid Baghaee Hospital in Ahvaz.

Methods: This correlational study was conducted on 106 eligible adult cancer patients who referred to the Oncology Ward of Shahid Baghaee Hospital in Ahvaz. The patients were chosen using convenience sampling. Data were collected by a demographic questionnaire, the Beck depression scale, and the self-compassion scale (SCS-LF). Data were analyzed by SPSS 20 using descriptive statistics and Pearson's correlation coefficient.

Results: This study recruited 106 cancer patients with a mean age of $41.14 \pm 15.12$ years. The majority of the subjects were male (61.3\%), married (65.1\%), and urban residents (68.9\%). Chemotherapy was the most used treatment in these patients (70.8\%). The mean scores of self-compassion and depression were $3.2 \pm 0.41$ and $19.87 \pm 12.55$, respectively. These results indicated a moderate level of selfcompassion and a high level of depression in the patients. There was a significant negative correlation between self-compassion and depression $(\mathrm{P}<0.05)$.

Conclusions: As the results of the present study indicated the high prevalence of depression in the studied patients and a negative relationship between depression and self-compassion, it is necessary to perform psychological interventions with an emphasis on compassion component to reduce depression in these patients.
\end{abstract}

Keywords: Depression, Self-Compassion, Cancer, Iran

\section{Background}

Cancer is the second cause of mortality in human populations after cardiovascular disease (1). Cancer includes a broad spectrum of diseases (over 270 types of diseases) (2). It is currently a major health issue in Iran and around the globe. According to estimates, one out of every five people is diagnosed with a form of cancer. Statistics on cancer in Iran follow the same rule (3).

Depression as a mood disorder is one of the most common psychiatric illnesses in cancer patients (3.4). It is characterized by a lack of pleasure, avoidance of friends or family, lack of motivation, intolerance to failure, reduced libido, decreased or increased appetite and weight, reduced energy, early fatigue, and sleep disorders (4). According to a report from the American Cancer Society, more than $25 \%$ of people with various types of cancer have clinical signs of depression (5). Depressed cancer patients usually have reduced health-related quality of life and report high levels of fatigue (6).

Self-compassion is the healthy form of self-sufficiency, which expresses the acceptance of undesirable aspects of self and own life. This concept consists of three main components of being kind to yourself, a sense of general self, and balanced awareness of personal excitement (7). The first component indicates that whenever a person becomes aware of his inefficiency, he tries to love and under- 
stand his existence. The second component is to recognize that pain is a common inevitable aspect of life experiences of all human beings. Ultimately, self-compassion represents a balanced awareness of self-emotions, including the ability to dealing with painful thoughts and feelings without exaggerating or feeling sad and regrettable for self. A high level of self-compassion can protect a person against disease and even death (8).

Several studies have shown that compassion by its own is a powerful predictor of mental health and increasing self-compassion improves psychological well-being over time (9). The study by Golpour et al. showed that cognitive self-compassion training and emotion-focused therapy were effective in improving the quality of life of depressed students (8). The results of a study showed that participants enjoyed compassion with the two main qualities of kindness and action. Participants stated that selfcompassion is important in their experiences and helps them deal with depression and anxiety. Nevertheless, the participants believed that it was difficult for them to have self-compassion (10).

\section{Objectives}

The literature lacks extensive studies in this area and there is no clear evidence of this issue, suggesting the need for further investigation to determine the relationship between depression and self-compassion in people with cancer. Therefore, due to the high prevalence of cancer and depression disorders in cancer patients and the need to determine other factors related to depression, the researchers intend to conduct a study aimed to determine the relationship between self-compassion and depression in cancer patients referring to the Oncology Ward of Shahid Baghaee Hospital in Ahvaz, Iran.

\section{Methods}

This correlational study was conducted on 106 cancer patients undergoing surgery, chemotherapy, or radiotherapy in the Oncology Ward of Ahvaz Shahid Baghaee Hospital in 2017. The eligible cancer patients were enrolled in the study by using a convenience non-probable sampling method. The sample size was determined using the following formula $(\mathrm{Z}=0.95, \mathrm{P}=0.17$, and $\mathrm{d}=0.05)$ :

$n=\frac{Z_{1-\frac{\alpha}{2}} \times P(1-P)}{d^{2}}$

The inclusion criteria included cancer patients diagnosed and confirmed by a specialist, undergoing surgery, chemotherapy, or radiation therapy, being able to read and write, being willing to participate in the study, and being free from mental and cognitive diseases. Subjects with incomplete questionnaires were excluded from the study. Data were collected after taking permission from the officials of the selected hospital, informing the participants about the purpose of the study, ensuring them about the confidentiality of their information, and asking them to sign the written consent form.

\subsection{Data Collection Tools}

The self-report method was used for data collection. Data collection tools consisted of a demographic questionnaire, the Beck depression scale, and the self-compassion scale(SCS). The demographic questionnaire included questions related to variables such as age, gender, marital status, education level, and duration of diagnosis.

\subsubsection{Beck Depression Inventory}

The 21-item self-report Beck depression inventory developed by Beck et al. is used extensively in clinical settings. Each item of the 21 items is rated on a four-point Likert-type scale ranging from 0 to 3 , based on the severity in the last two weeks. The total score ranges from 0 to 63, with higher scores indicating more severe depressive symptoms. A total score of 0 to 9 indicates no depression, a score of 10 to 19 mild depression, a score of 20 to 29 moderate depression, a score of 30 to 39 severe depression, and a score of 40 or above extreme depression (11).

\subsubsection{The Self-Compassion Scale (SCS)}

The 26-item self-report self-compassion scale was created by Neff in 2003. The scale consists of six intercorrelated factors: self-kindness (four items), selfjudgment (four items), common humanity (four items), isolation (four items), mindfulness (four items), and over-identification (four items). The SCS items are scored on a five-point Likert scale (from 1 to 5). Self-kindness, common humanity, and mindfulness contain positively formulated items while self-judgment, isolation, and overidentification contain negatively formulated items. The total score of the scale ranges from 26 to 130 with higher scores indicating greater self-compassion (12).

\subsection{Validity and Reliability of the Study Tools}

The validity of the Persian version of the Beck Depression Inventory was confirmed and its reliability was reported to be more than 0.6 (13). According to Neff, the SCS has good internal consistency reliability (0.92), as well as good test-retest reliability $(r=0.93)$ over a three-week interval (12). Golpour et al. reported Cronbach's alpha coefficients for the total scale and its subscales in the range of 0.65 to $0.92(8)$. 


\subsection{Data Analysis}

SPSS version 20 software was used to analyze the data. Descriptive statistics including frequency and percentage were used to describe the data. Independent $t$-test, ANOVA test (for the relationship between demographic variables and the main variables), and Pearson correlation coefficient were used for normally distributed data. In the case of non-normality of data, the Mann-Whitney, KruskalWallis, and Spearman tests were used.

\subsection{Ethical Considerations}

The Ethics Committee of Ahvaz Jundishapur University of Medical Sciences (IR.AJUMS.REC.1396.176) approved the study. The researchers were trained on ethical issues such as respect for the right to participate voluntary, obtaining consent to participate in research, and informing the participants about the purpose of the study.

\section{Results}

The mean age of the participants was $41.14 \pm 15.12$ years. The majority of the participants were male (61.3\%), married (65.1\%), and urban residents (68.9\%). Chemotherapy was the most common treatment in the patients (70.8\%) (Table 1). The mean scores of self-compassion and depression were $3.2 \pm 0.41$ and $19.87 \pm 12.55$, respectively, indicating a moderate level of self-compassion and depression in the studied patients (Table 2). There was a significant reverse correlation between the mean score of depression and the mean score of self-compassion and its subscales $(\mathrm{P}<0.05)$, except for the feeling of human commonality.

\section{Discussion}

This study aimed to determine the relationship between self-compassion and depression in cancer patients referring to the Oncology Ward of Shahid Baghaee Hospital in Ahvaz, Iran. The results showed that self-compassion and depression in the studied patients were at a moderate level. In a study conducted by Alizadeh et al. on women with breast cancer, the results showed that selfcompassion was at a moderate level in the studied sample, which corroborates our results (14). In the study by Park et al., although anxiety symptoms were highly experienced by young women with newly diagnosed metastatic breast cancer, depression was less common (15).

Our findings showed that there were significant reverse correlations between depression and selfcompassion and its subscales, except for the feeling of human commonality. It means that the lower is selfcompassion, the higher is depression prevalence in the studied patients. In this regard, the results by Rajabi et al. indicated a negative relationship between selfcompassion and depression (16). Other studies conducted on cancer patients demonstrated that higher levels of self-compassion had significant relationships with lower depressive and stress symptoms (17-19), higher mental health and quality of life $(18,19)$, and higher resilience to breast cancer (14). According to a literature review by Sirois and Rowse, self-compassion is in connection with adaptive coping, lower stress and distress, and the practice of important health behaviors in chronic illness populations (20). Arambasic et al. in their study concluded that self-compassion training may be useful for enhancing psychological adjustment in long-term breast cancer survivors (21). In other words, self-compassion can help chronic patients, especially cancer patients, to maintain their mental health and thus, their general health, more effectively. Self-compassion works by creating some positive attributes such as patience, tolerance, self-esteem, and balance of excitement as an antidepressant. In fact, self-compassion can act as a protective factor against depression. Through compassion and kindness toward oneself and others and accepting unpleasant events, it can help improve depression and shorten the course of treatment (16). Therefore, it seems that with strengthening the sense of self-compassion, one can expect reduced depression in cancer patients.

The current study has limitations that require attention. An important limitation is the study's correlational cross-sectional nature that limits to establish a causal relationship. Our hypothesis based on the evidence was that higher self-compassion leads to a lower risk of depression in cancer patients; however, our results only indicated a relationship between the two variables and did not indicate the direction of the relationship. In order to determine the causal relationship between the two main studied variables, future studies should employ a longitudinal design to assure that the direction of causation is as hypothesized. The second limitation is the use of convenience sampling in a single clinical setting (which is, of course, the most important referral unit for cancer patients in the city), which can limit the generalizability of the findings to other populations.

\subsection{Conclusions}

The results of the present study indicate that selfcompassion and depression were at a moderate level in cancer patients and there was a negative correlation between depression and self-compassion. Therefore, it is necessary to perform psychological interventions, with an emphasis on compassion component, to reduce depression 


\begin{tabular}{|c|c|c|c|}
\hline Variable & Frequency (\%) & Depression P Value & Self-Compassion P Value \\
\hline Gender & & 0.29 & 0.14 \\
\hline Male & 61.3 & & \\
\hline Female & 38.7 & & \\
\hline Marital status & & 0.79 & 0.59 \\
\hline Single & 22.6 & & \\
\hline Married & 65.1 & & \\
\hline Divorced & 2.8 & & \\
\hline Widowed & 9.4 & & \\
\hline Place of residence & & 0.08 & 0.45 \\
\hline Urban & 68.9 & & \\
\hline Rural & 31.1 & & \\
\hline Education level & & 0.36 & 0.15 \\
\hline Illiterate & 24.5 & & \\
\hline Under diploma & 31.1 & & \\
\hline Diploma & 26.4 & & \\
\hline Associate degree & 7.5 & & \\
\hline Graduate or post-graduate & 10.4 & & \\
\hline History of surgery & & 0.79 & 0.60 \\
\hline Yes & 35.8 & & \\
\hline No & 64.2 & & \\
\hline Type of treatment & & 0.18 & $0.01^{\mathrm{a}}$ \\
\hline Chemotherapy & 70.8 & & \\
\hline Radiotherapy & 2.8 & & \\
\hline Chemotherapy + Surgery & 14.2 & & \\
\hline Chemotherapy + Radiotherapy + Surgery & 6.6 & & \\
\hline other & 5.7 & & \\
\hline
\end{tabular}

${ }^{\mathrm{a}}$ Significant at the level of below 0.05 .

$\overline{\text { Table 2. The Mean Scores of Depression and Self-Compassion in Studied Cancer Pa- }}$ tients

\begin{tabular}{|cc}
\hline Variables & Mean \pm SD \\
\hline Self-compassion & $3.2 \pm 0.41$ \\
\hline Self-compassion subscales & \\
\hline Self-kindness & $3.28 \pm 0.71$ \\
\hline Self-judgment & $3.30 \pm 0.77$ \\
\hline Common humanity & $3.22 \pm 0.82$ \\
\hline Isolation & $3.09 \pm 0.71$ \\
\hline Mindfulness & $3.4 \pm 0.73$ \\
\hline Over-identification & $3.03 \pm 0.79$ \\
\hline Depression & $19.87 \pm 12.55$ \\
\hline
\end{tabular}

in cancer patients. The identification of other depressionrelated components can help increase the current knowledge of depression in patients and design effective nursing and psychological interventions.

\section{Acknowledgments}

This paper is the result of a research project approved and financially supported by the Student Research Committee of Ahvaz Jundishapur University of Medical Sciences (95s69). We appreciate the financial support and assistance of all patients and nurses of Shahid Baghee hospital, Ahvaz, Iran.

\section{Footnotes}

Authors' Contribution: Yaghoob Madmoli contributed in study conception, study designing, data collection, data analysis, drafting the manuscript. Mahin Gheibizadeh contributed in study conception, study designing, data analysis, drafting and revision of the manuscript.

Conflict of Interests: There are no conflicts of interest.

Ethical Approval: The Ethics Committee of Ahvaz Jundishapur University of Medical Sciences (IR.AJUMS.REC.1396.176) approved the study.

Funding/Support: This research project financially supported by the Student Research Committee of Ahvaz Jundishapur University of Medical Sciences (95s69). 


\section{References}

1. Haghighi F, Khodaei S, Sharifzadeh GR. [Effect of logotherapy group counseling on depression in breast cancer patients]. Mod Care J. 2012;9(3):165-72. Persian.

2. Aghabarari M, Ahmadi F, Aghaalinejad H, Mohammadi E, Hajizadeh E. [Effect of designed exercise program on stress, anxiety and depression in women with breast cancer receiving chemotherapy]. $J$ Shahrekord Univ Med Sci. 2008;9(4):26-35. Persian.

3. Khodai S, Dastgerdi R, Haghighi F, Sadatjoo SA, Keramati A. [The effect of cognitive-behavioral group therapy on depression in patients with cancer]. J Birjand Univ Med Sci. 2011;18(3):183-90. Persian.

4. Rajabizadeh G, Mansoori SM, Shakibi MR, Ramazani MR. [Determination of factors related to depression in cancer patients of the oncology ward in Kerman]. J Kerman Univ Med Sci. 2005;12(2):142-7. Persian.

5. Farzin Rad B, Asgharnejad Farid AA, Yekkeh Yazdandoust R, Habibi Asgarabad $\mathrm{M}$. [Comparison of copying strategies and personality styles in depressed and non-depressed students].J Behav Sci. 2010;4(1):17-21. Persian.

6. Atrifard M, Zahiredin A, Dibaei S, Zahed G. [Comparing depression in children and adolescents with cancer with healthy ones].JUrmia Univ Med Sci. 2014;25(1):21-31. Persian.

7. Bashar Pour S, Eisazadegan A. [Investigate the role of Self-Compassion personality traits and forgiveness in predicting the severity of depression]. J Behav Sci. 2011;10(6):452-61. Persian.

8. Golpour R, Abolghasemi A, Ahadi B, Narimani M. [The effectiveness of cognitive self-compassion training and emotion-focused therapy on quality of life with depression disorder].J Clin Psychol. 2014;6(1):53-64. Persian.

9. Abolghasemi A, Taghipour M, Narimani M. [The relationship of type" D" personality, self-compassion and social support with health behaviors in patients with coronary heart disease]. Health Psychol. 2012;1(1):1-12. Persian.

10. Raes F. Rumination and worry as mediators of the relationship between self-compassion and depression and anxiety. Pers Individ Differ. 2010;48(6):757-61. doi: 10.1016/j.paid.2010.01.023.

11. Beck AT, Steer RA, Carbin MG. Psychometric properties of the Beck depression inventory: Twenty-five years of evaluation. Clin Psychol Rev. 1988;8(1):77-100. doi: 10.1016/0272-7358(88)90050-5.
12. Neff KD. The development and validation of a scale to measure self-compassion. Self Identity. 2003;2(3):223-50. doi: $10.1080 / 15298860309027$.

13. Makvandi B, Heidarei AR, Najarian B, Asgari P. The relation between alexithymia with emotional intelligence, anxiety and depression in boys students of Islamic Azad University, Ahvaz Branch. Knowl Res Appl Psychol. 2012;13(47):83-91.

14. Alizadeh S, Khanahmadi S, Vedadhir A, Barjasteh S. The relationship between resilience with self- compassion, social support and sense of belonging in women with breast cancer. Asian Pac $J$ Cancer Prev. 2018;19(9):2469-74. doi: 10.22034/APJCP.2018.19.9.2469. [PubMed: 30255701]. [PubMed Central: PMC6249445].

15. Park EM, Gelber S, Rosenberg SM, Seah DSE, Schapira L, Come SE, et al. Anxiety and depression in young women with metastatic breast cancer: A cross-sectional study. Psychosomatics. 2018;59(3):251-8. doi: 10.1016/j.psym.2018.01.007. [PubMed: 29525523]. [PubMed Central: PMC5935568].

16. Rajabi G, Gashtil K, Amanallahi A. [The relationship between self-compassion and depression with mediating's thought rumination and worry in female nurses]. Iran J Nurs. 2016;29(99):10-21. Persian. doi: 10.29252/ijn.29.99.100.10.

17. Korner A, Coroiu A, Copeland L, Gomez-Garibello C, Albani C, Zenger $\mathrm{M}$, et al. The role of self-compassion in buffering symptoms of depression in the general population. PLoS One. 2015;10(10). e0136598. doi: 10.1371/journal.pone.0136598. [PubMed: 26430893]. [PubMed Central: PMC4591980].

18. Pinto-Gouveia J, Duarte C, Matos M, Fraguas S. The protective role of self-compassion in relation to psychopathology symptoms and quality of life in chronic and in cancer patients. Clin Psychol Psychother. 2014;21(4):311-23. doi: 10.1002/cpp.1838. [PubMed: 23526623].

19. Raque-Bogdan TL, Ericson SK, Jackson J, Martin HM, Bryan NA. Attachment and mental and physical health: Self-compassion and mattering as mediators. J Couns Psychol. 2011;58(2):272-8. doi: 10.1037/a0023041. [PubMed: 21463033].

20. Sirois FM, Rowse G. The role of self-compassion in chronic illness care. J Clin Outcomes Manag. 2016;23(11):521-7.

21. Arambasic J, Sherman KA, Elder E; Breast Cancer Network Australia. Attachment styles, self-compassion, and psychological adjustment in long-term breast cancer survivors. Psychooncology. 2019;28(5):1134-41. doi: 10.1002/pon.5068. [PubMed: 30892774]. 